\title{
Use of a Design Canvas in a Robotics Workshop and Analysis of its Efficacy (Fundamental)
}

\section{Mr. Abhidipta Mallik, NYU Tandon School of Engineering}

Abhidipta Mallik received his B.Tech. degree in Electronics and Communication Engineering from the West Bengal University of Technology, Kolkata, India, and M.Tech. degree in Mechatronics from the Indian Institute of Engineering Science and Technology, Shibpur, West Bengal, India. He has one year and ten months of research experience at the CSIR-CMERI, India. He is currently a Ph.D. student in Mechanical Engineering at NYU Tandon School of Engineering, Brooklyn, NY, where he is serving as a research assistant under an NSF-funded ITEST project.

\section{Dr. Sheila Borges Rajguru, NYU Tandon School of Engineering}

Dr. Sheila Borges Rajguru is the Assistant Director of the Center for K-12 STEM Education, NYU Tandon School of Engineering. As the Center's STEAM educator and researcher she works with engineers and faculty to provide professional development to K-12 STEM teachers with a focus on social justice. She is currently Co-Principal Investigator on two NSF-grants (senior personnel of one) that provide robotics/mechatronics PD to science, math, and technology teachers. In addition, she is the projects director of the ARISE program. This full-time, seven-week program includes: college level workshops and seminars, and a high level research experience in NYU faculty labs. Her commitment to diversity and equity is paramount to her work in STEAM and activism. As a former Adjunct Professor at Teachers College, Columbia University and biomedical scientist in immunology Dr. Borges balances the world of what scientists do and brings that to STEAM education in order to provide culturally relevant professional development and curricula that aligns to the Next Generation Science Standards (NGSS). Moreover, Dr. Borges is treasurer and co-chair of the Northeastern Association of Science Teacher Education (NE-ASTE) where faculty, researchers, and educators discuss present STEM teaching and learning and influence policy.

\section{Dr. Vikram Kapila, NYU Tandon School of Engineering}

Vikram Kapila is a Professor of Mechanical Engineering at NYU Tandon School of Engineering (NYU Tandon), where he directs a Mechatronics, Controls, and Robotics Laboratory, a Research Experience for Teachers Site in Mechatronics and Entrepreneurship, a DR K-12 research project, and an ITEST research project, all funded by NSF. He has held visiting positions with the Air Force Research Laboratories in Dayton, OH. His research interests include K-12 STEM education, mechatronics, robotics, and control system technology. Under a Research Experience for Teachers Site, a DR K-12 project, and GK-12 Fellows programs, funded by NSF, and the Central Brooklyn STEM Initiative (CBSI), funded by six philanthropic foundations, he has conducted significant K-12 education, training, mentoring, and outreach activities to integrate engineering concepts in science classrooms and labs of dozens of New York City public schools. He received NYU Tandon's 2002, 2008, 2011, and 2014 Jacobs Excellence in Education Award, 2002 Jacobs Innovation Grant, 2003 Distinguished Teacher Award, and 2012 Inaugural Distinguished Award for Excellence in the category Inspiration through Leadership. Moreover, he is a recipient of 2014-2015 University Distinguished Teaching Award at NYU. His scholarly activities have included 3 edited books, 9 chapters in edited books, 1 book review, 62 journal articles, and 154 conference papers. He has mentored 1 B.S., 35 M.S., and 5 Ph.D. thesis students; 58 undergraduate research students and 11 undergraduate senior design project teams; over $500 \mathrm{~K}-12$ teachers and 118 high school student researchers; and 18 undergraduate GK-12 Fellows and 59 graduate GK-12 Fellows. Moreover, he directs K-12 education, training, mentoring, and outreach programs that enrich the STEM education of over 1,000 students annually. 


\section{Use of a Design Canvas in a Robotics Workshop and Analysis of its Efficacy (Fundamental)}

\section{Introduction}

Advances in science and technology are shaping every aspect of our lives including education, work, healthcare, transportation, commerce, and entertainment. This unfolding societal transformation is creating a growing demand for a workforce that is well-trained in science, technology, engineering and mathematics (STEM) fields and that is additionally representative of societal diversity. To meet this demand, the K-12 educational environment is witnessing a growing focus on the use of advance technologies for engaging and exposing all students in STEM disciplines [1],[2]. Teaching and preparing students for success in the technology-rich environment of workplace requires teachers who have the knowledge, comfort, and capacity to adapt and integrate new technologies for classroom teaching and learning. Moreover, the Next Generation Science Standards (NGSS) [3],[4], which are national standards to reenvision and enhance STEM education, emphasize the need for integrating practices of engineering and the engineering design process (EDP) [5],[6] in K-12 classrooms. As one contribution to this growing need, we developed a robotics education workshop for high school teachers and their students to collaboratively learn and practice fundamental engineering and robotics concepts during summer and then utilize this knowledge in classroom during the academic year.

A fundamental step in the engineering (robotics) design process is to draw on engineering principles for performing rigorous analyses and studying the efficacy of a proposed design [7] before committing financial, human, and material resources to build it. This includes analyzing every feature of the designed product (robotics artifact) to ensure overall quality and examine impact on cost, considering ways in which it could fail and refining it, before transforming the design into a physical device that is of interest to customers. Other important aspects of such evaluation include being mindful of the current economic conditions as well as the aesthetics and usability of the newly designed product to ensure that it appeals to consumers [8] who expect unique and exciting products. Thus, educational preparation of the STEM workforce must go beyond technical content and ought to cultivate students' entrepreneurial knowledge, skills, and attitude so that they understand target markets and make valuable contributions.

Recent years have witnessed a growing interest in adapting canvas techniques such as Business Model Canvas in educational environments to support student exploration and learning of the fundamental concepts of entrepreneurship and business development as well as their interconnections [9]. Inspired from the success of canvas tools in entrepreneurship and business development disciplines, educators have begun to adapt and examine novel canvas tools for engineering education, especially in the realm of product design and development. As one 
illustration, recently Kline et al. [9] created a Design Canvas by using a model-based methodology that engages the users in acquiring and analyzing myriad relevant data in an engineering design project while being responsive to the business context. This paper describes how the design canvas of [9] was adapted and operationalized in a robotics education workshop and highlights its benefits.

\section{Literature Review}

While the use of robotics in educational environment is not a panacea, it has been reported that teachers who are positively disposed and committed to technology deem it acceptable to use robots in STEM classrooms [10]. Moreover, building on the popularity of various robotics competitions in the K-12 environment, teaching and learning about robotics as a discipline has attracted increased attention [11],[12]. Nonetheless, educational preparation of K-12 and postsecondary students seeking to learn about robotics needs to transition beyond purely technical education so that they can be afforded broader career opportunities [8]. For example, 48\% of engineering graduates who took elective courses in entrepreneurship as undergraduates started their own businesses [13]. In fact, a majority of engineering students believe that it is beneficial to have entrepreneurship courses in the curriculum [14]. Thus, there is an urgent need to impart entrepreneurial knowledge and skills to students to help them understand the market and make valuable contribution to society [8]. This is especially important for students of engineering who plan to start their own ventures. Moreover, having received entrepreneurial education, engineers who serve in established enterprises are well equipped to participate in, manage, and lead teams and contribute to their business units as innovators [8] by drawing on their ability to address engineering from a societal point of view [15].

Entrepreneurship education can additionally provide students experiences in prototyping and product design and develop their market analysis skills [8]. However, entrepreneurship is not only about the creation of a business model or launching a new business. Instead, it is an endeavor with salient features like seeking opportunities and taking risks beyond security [16]. A majority of engineering students believe that their career prospects would improve with entrepreneurship courses and students who are exposed to entrepreneurship courses have better entrepreneurial selfefficacy [17]. Hence, students who took entrepreneurship courses showed more interest in starting their own business than others. Motivated by the aforementioned reasons, and by further considering [18],[19], entrepreneurship was included as an integral component of the robotics education workshop for high school participants conducted at the NYU Tandon School of Engineering in summer 2018.

To effectively and seamlessly integrate robotics and entrepreneurship in our curriculum, the project team brainstormed and envisioned real-world projects (discussed in later sections) as design challenges for summer workshop participants. Moreover, to enable the participants learn business development and product design concepts in a systematic and effective manner, canvas 
techniques were introduced to the workshop participants. As noted in [20], novice designers often do not collect enough or accurate information prior to starting the design process [20]. Furthermore, after beginning the design process, such designers do not follow a systematic design process. Alternatively, expert designers, who follow a business canvas [21], conduct formal and rigorous research prior to initiating the design process. They engage in identifying, exploring, discussing, critiquing, and discarding many ideas and approaches for the design problem. They consider myriad tradeoffs for competing strategies and start the formal design process only after a thorough vetting of all suggestions. Next, expert designers follow a systematic and interactive process to continually iterate their design based on feedback from various stakeholders [20]. When a design team begins by identifying the unmet needs of customers and comprehends their corresponding challenges [22], it develops an empathy with customers and gains a deeper appreciation of the design space - all of which contribute to the development of better products. In this regard, the canvas approach is particularly effective as it allows systematic collection, categorization, and synthesization of design-relevant information. With such a methodology, a comprehensive view of the design challenge is gained at an abstract level that can be followed with concrete steps of detailed design exploration, extensive modeling, and physical prototyping, among others. In advancing through the various stages of product design and development, the design canvas allows refocusing of effort in the areas requiring further attention. In this manner, through repeated iteration both the product design and the design process itself are improved [20].

An organization's business model can be characterized by using nine basic building blocks [21]. While the nine building blocks can provide a common means of understanding to various stakeholders of the organization, it is not sufficient to simply know of these nine building blocks. Instead, to gain a deeper understanding of the organization, these nine constituent elements are mapped onto a pre-structured canvas called the business model canvas (BMC). By revealing the critical interactions between the organization's resources, activities, and partners, the BMC tool aids in designing, analyzing, planning, and inventing new business models. With the aid of an organization's BMC, a single graphic representation, one can readily gain an understanding of the underlying business, including its relationships, infrastructure, strategies, etc., be it a start-up entrepreneur or the most senior executive. Many existing canvas tools entail complex associations among its various elements and are thus more suitable for veteran entrepreneurs and advanced designers [23],[24]. To address the need for canvas tools for novice learners, recently [9] designed and developed a simpler design canvas model. The essential ingredient in the development of the design canvas tool of [9] is the $S^{*}$ Metamodel proposed in [25]. Specifically, according to [25], the $\mathrm{S} *$ Metamodel constitutes a minimal representation with which an engineering system can be described accurately. This $\mathrm{S}^{*}$ Metamodel framework provides the foundation for the development of the design canvas wherein the smallest amount of data is needed to represent the underlying system and characterize the relationship among its disparate components. See [25] for detailed explanations about how the $\mathrm{S}^{*}$ Metamodel framework is enacted to design models of engineering systems. 
In creating a business or design canvas tool with the aid of $S^{*}$ Metamodel, it is essential to identify the features that are sought after qualities of the system for a potential customer. For example, these may include: durability, affordability, usability, and reparability [9] that necessitate tradeoffs for decision-making. By using the $\mathrm{S}^{*}$ Metamodel, [9] created a design canvas wherein the following nine model components were isolated.

- Stakeholders include individuals or organizations interested in the end product of the system.

- Actors are individuals or organizations that directly interact with the system.

- Features are quantifiable metrics of sought after qualities, properties, or characteristics of the system.

- Interactions refer to the exchange of inputs and outputs between the system and actors.

- Modes refer to various operating conditions of system, e.g., on-off, charging, operating, etc.

- Inputs/outputs include energy, materials, or signals exchanged between the system and actors.

- Functions describe the behavior of the system and transform inputs into outputs.

- Components are physical subsystems or components of the system.

- Designs includes collection of components with allocated requirements to represent the system.

The model design canvas template of [9] is provided in Appendix 1. As an alternative to the nine component design canvas, [9] has also proposed a simpler design canvas with only six components. Moreover, several of the aforementioned components of the design canvas can be combined to gain a comprehensive view of the product design model. Such an approach also allows similar information and concepts to be categorized under a single label. In this manner, the nine components of design canvas can be reduced to yield a design canvas with the following three essential elements.

- Value collectively addresses stakeholders and features.

- Behavior is the synthesis of actors, modes, interactions, input/outputs, and functions.

- Design is concerned with the design and components.

An important aspect of this revised canvas model is that the elements are indirectly connected to one another and discovering the appropriate connection among the elements often is a key element of design [9].

In our summer robotics workshop, most participants worked on robotics design projects for the first time in their educational careers. Thus, the workshop instructors needed to make appropriate changes to their instructional approach to match the different learning needs of the participants. The integration of the design canvas model during the robotics design projects served particularly well since it provided a formative assessment to the instructors about their instructional strategy. 


\section{Professional Development Structure}

\subsection{Participants and facilitators}

The robotics workshop was a four-week summer program consisting of two weeks of guided learning and two weeks of robotics product development. The workshop was attended by 16 teachers (male: nine, female: seven, underrepresented: 10) and 36 students (male: 24, female: 12, underrepresented: 20) from 12 inner-city high schools. Among the 16 teachers were 10 science teachers, five math teachers, and one foreign language teacher. The workshop was held under the Innovative Technology Experiences for Students and Teachers (ITEST) program of the U.S. National Science Foundation. Facilitators included engineering and education faculty, who supervised all personnel, curricula, and instructional aspects of the workshop, and graduate engineering students, with theoretical and practical knowledge of robotics through coursework and research, who delivered the lectures and conducted all hands-on learning sessions.

\subsection{Curriculum}

Throughout the two weeks of guided learning period, workshop participants performed numerous structured projects for experiential learning. Twenty sessions were conducted during guided learning, with one session in the morning and another in the afternoon of each day. In each session, participants were provided a short introduction (under an hour) to scientific, mathematical, and engineering concepts underpinning the session's focus area and they devoted a significant time (three hours) to hands-on learning and exploration. Starting with the introductory and motivating lessons on fundamentals of robotics [12], they gradually learned and practiced the major concepts of mobile robots [26]. Lessons included physics concepts such as forces, momentum, equilibrium, stability, center of mass, center of gravity, etc., which are important for robot chassis construction. They additionally learned about different types of motors such as DC motor and servomotor and their uses, drive mechanisms for mobile robotics (e.g., differential, holonomic, skid, swerve, crab, and Ackermann), and different types of wheels such as omnidirectional and Mecanum. They also received introduction to different coordinate systems such as Cartesian and polar coordinates. One entire session was dedicated to learning about 3D printing technologies by using the Tinkercad software [27]. Lessons were also delivered to give participants an understanding of and familiarity with basic electrical and electronic components such as conductors, insulators, resistors, capacitors, batteries, switches, diodes, LEDs, speakers, motors, etc. In addition, they learned about Ohm's law, voltage-current relations, series/parallel networks, analog and digital signals, Boolean algebra, and logic gates [28]. They additionally received lessons on the operating principles of sensors and electrical schematic for interfacing the Arduino microcontroller [29] with various sensors, e.g., infrared (IR), photoresistor, ultrasonic, etc. They learned about various elements of 
Arduino programming (e.g., control structures, communicating with a serial monitor, arithmetic operations, conditional operators, loops, binary-decimal conversion, etc.) [29].

Corresponding to each lesson on fundamental concepts of robotics, there was a hands-on session wherein the participants applied the knowledge gained from lectures. They were divided into teams for the hands-on activities with each team consisting of two teachers and three to four students. In one hands-on session the participants used the VEX Robotics Clawbot kit [30] to build a mobile wheeled robot. In another hands-on session the participants used the Arduino microcontroller to control the robot to perform various tasks such as moving forward and backward a specified amount of distance and turning by a specified angle.

Two days (four sessions) were dedicated to learn about entrepreneurship through experiential activities. In these sessions, the participants learned about business planning with a focus on business model canvas [21]. Moreover, they learned about the product development process and market analysis using tools such as product market matrix [31], Porter's 5 forces [32], and technology S-curve [33], among others. Next, they learned in detail different methods of raising capital, e.g., venture capital, crowd funding, strategic alliances, grants, etc. Additional learning activities focused on social entrepreneurship and managing intellectual property. A special focus of the entrepreneurship session was on a visit to the university-based startup incubators.

\section{Projects}

In the last two weeks of the robotics workshop (Weeks 3 and 4), participants worked on two projects. In the first project (during Week 3), the teacher-student teams developed their robotics creations (including designing, prototyping, testing, and evaluating the mechanical structure, drive mechanism, sensor and drive electronics, computer interfaces, and microcontroller program) to compete on a mock-up game field inspired from a real-world scenario of a coffee shop in which a "robot waiter" delivers coffee cups to patrons sitting around different tables [34],[35]. Figure 1 shows the project schematic. There were twelve tables numbered 1 to 12 on the game field. The primary task of the robot was to pick a cup from the START position and deliver it to a table specified by the facilitator at the start of demonstration. The teams could input the table number to the robot using a potentiometer, a button, or any other input means. It was suggested that they might find it useful to display the entered input for verification purposes. The robot was to deliver cups one by one to correct tables by employing its line following capability along with the algorithms participants programmed. The algorithm and design of the robot were open-ended problems left to the participants. For example, teams could utilize three IR sensors or two IR and an ultrasonic sensor for this project to detect where and when to make turn, move forward, or stop.

The second project was a continuation of the waiter robot project from Week 3 of the workshop. In this project, the teams were supposed to compete on the mock-up game field of Figure 1 
wherein, as instructed, the waiter robot both delivers coffee cups to tables and collects coffee cups from tables after a customer finishes his/her coffee. That is, in the Week 3 project participants developed robots that could only deliver coffee cups. However, for the Week 4, project teams needed to develop robots that could additionally collect coffee cups from tables. During project demonstration, two teams were to work on the game field together. At the start of the demonstration, the facilitators selected robot of one team as a delivery robot and the other team's robot as a cleaning robot. The robot assigned as the delivery robot had to pick a cup from the START position and deliver it to a table specified by the facilitator at the start of demonstration. The cleaning robot had to start from the START position and go to the same table after a certain delay and collect the cup and bring it back to the START position. One caveat given to the participants was that the delivery and cleaning robots should not collide with one another at any time.

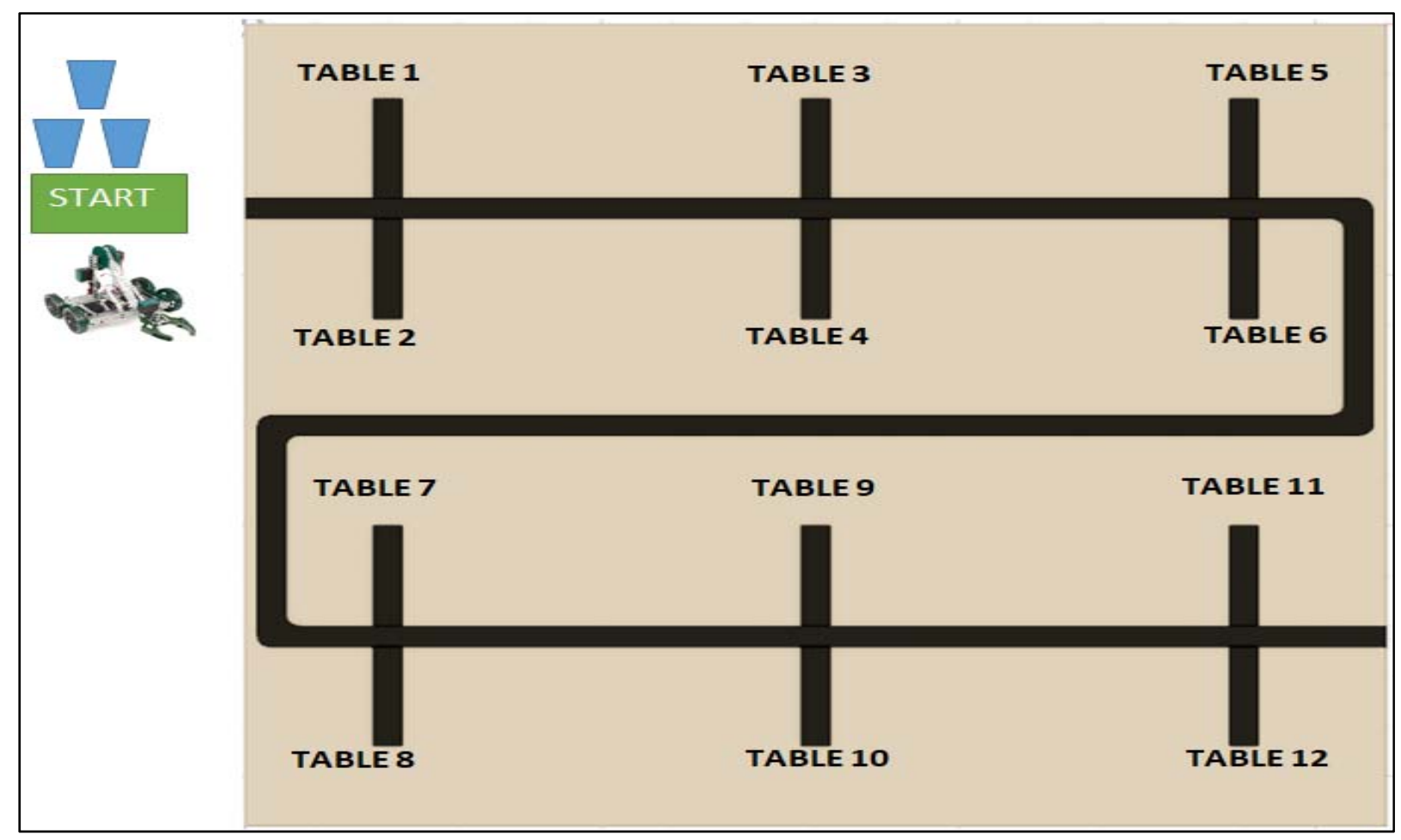

Figure 1: Project schematic.

\section{Research Procedure}

The research reported in this paper was conducted during the last two weeks (Weeks 3 and 4) of the workshop when the participants designed and prototyped their robots for the assigned projects. For the project sessions, the participants were grouped into nine teams, with each team comprising of approximately two teachers and four students. The nine teams were assigned to two classrooms by a lottery, with one classroom housing four teams and another housing five teams. One of these 
two classrooms was randomly selected as the treatment group, which included four teams. The remaining five teams constituted the control group. Based on the observations of the facilitators from the first two weeks of the program, both groups consisted of some strong teams and others that were still developing in their abilities. The membership information of the treatment and control groups is provided in Table 1. Throughout the two-week project assignments, these two groups continued to work on their prototypes in separate classrooms and were instructed not to interact with one-another during occasional meetings for testing and experimentation.

Table 1: Treatment and control group constituents.

\begin{tabular}{|c|c|c|}
\hline Particulars & Treatment group & Control group \\
\hline Teams & 4 & 5 \\
\hline Total students & 16 & 20 \\
\hline Total teachers & 7 & 9 \\
\hline
\end{tabular}

At the start of Week 3, the members of the treatment group were provided a formal introduction to the design canvas model of Kline et al. [9]. First, they were informed about the differences between the approaches of novice vs. informed designers. The benefits of various approaches of informed designers were highlighted to encourage the treatment group members to follow their lead. Second, the S*Metamodel and meta-analysis of models was also highlighted to them. Third, they learned about the nine components of the design canvas and their interactions. Furthermore, the process of reducing the full design canvas to a simplified design canvas with three essential elements was explained to them. Fourth, the IDEO Shopping Cart [9] provided an illustrative application study of the design canvas to a real-world problem. Finally, the treatment group members were advised to follow a similar approach for their own projects. Throughout the project activities in Weeks 3 and 4, they were periodically encouraged to make a deliberate use of the design canvas framework in their own robotics product development exercise. As evidenced below, the use of design canvas supports the EDP [5]. Specifically, beginning with defining and understanding the problem, the participants were encouraged to carry out extensive background research. This was followed by brainstorming solutions with group members and choosing the best solution through diverse considerations and experimentations. Once the prototype was built, test and evaluation were carried out and the solution was communicated through presentations and demonstrations. Finally, time permitting, the participants iteratively improved their solutions through redesign.

The performance of each team in the treatment and control groups was individually evaluated 16 times over the two-week duration by undergraduate engineering students serving as evaluators who were not informed whether a particular team belonged to the treatment or control group. In fact, the artifacts and documents related to design canvas were removed from the treatment group classroom prior to each visit by the evaluators. Moreover, the teams in the treatment group were instructed not to explicitly discuss their design canvas with the evaluators. The evaluation team consisted of six undergraduate engineering students (one female, five males, three Caucasians, and 
three Asians) who were serving as summer research interns in the Mechatronics, Controls, and Robotics Laboratory at NYU Tandon. Being engineering students themselves, the evaluators were exposed to engineering and robotics design through coursework and research. They were explained the two robotics design projects two weeks prior to the start of the workshop. Moreover, they were informed about the purpose and process of evaluation through a formal presentation and videos by graduate engineering students who served as project facilitators and who had prior experiences in conducting K-12 STEM education projects. It was emphasized to the evaluators that for research purposes their assessment of the participants needed to be genuine and unbiased. The evaluators considered the following five factors in assessing each team: understanding of problem statement, information and knowledge gathering, idea generation, design tradeoff, and idea and design iterations (see Appendix 2). The evaluators individually rated each of these factors for each team on a scale of 100 (see Appendix 3 for the evaluation rubric adapted from [36]). Their rating of each team was guided by interviews of team members to assess their progress in various aspects of the robot design projects. The evaluation visits for each team lasted approximately 10 minutes and were undertaken every other day in the afternoon by three to four evaluators.

\section{Results}

\subsection{Quantitative ratings}

The following results are based on an analysis of the 16 ratings of each team by the evaluators (Evaluation Day 1, 2, 3, 4, and 5 having 3, 4, 3, 3, and 3, evaluators, respectively). Having been introduced to the design canvas model and periodically reminded to use it, the teams in the treatment group performed better than the teams in the control group. In fact, the teams in the treatment group achieved higher average ratings than the teams in the control group for 15 out of the 16 ratings. Combining the 16 individual evaluations, the treatment group achieved an average score of 94.3 out of $100 \mathrm{vs}$. the control group average score of 88.2. Figure 2 shows the treatment and control group evaluation scores plotted as bar graphs where individual bars represent the average score awarded by an individual evaluator on the indicated day. As evidenced from Figure 2 , only for evaluation ID \#10, the average score awarded by one evaluator to the control group is higher than that for the treatment group. However, for the other 15 evaluations, the average score awarded by the evaluators to the treatment group is higher than the control group score.

The data of Figure 2 illustrates that the teams in the treatment group performed better than the teams in the control group on the projects. There are several reasons for the better average performance of the treatment group. While all workshop participants received an introduction to the business model canvass [21] as part of their entrepreneurship learning, only the participants in the treatment group received guided exposure to the design canvas model [9]. Thus, the teams in the treatment group were concerned with the overall design as well as the individual aspects of their designs. When the evaluators interviewed teams, they first tried to establish a clear 
understanding of problem statement exhibited by each member of the team. For a successful project, before starting any design or prototyping work, it is imperative that team members collectively perceive the project by discussing their understanding. The teams were assessed based on the amount, quality, and diversity of their efforts to gather information and knowledge through literature search, web search, and user surveys. As in any engineering product design project, for the current activity, it was of paramount importance that the teams engage in: generating ideas through collective discussion; assessing multiple ideas and coopting or rejecting them collectively; demonstrating out-of-the-box thinking; and iterating on ideas and designs. The evaluators carefully reviewed whether the teams considered design tradeoffs such as: accuracy vs. speed, durability vs. light weight, etc. They considered whether the design teams considered modularity in their designs for robot hardware and control algorithms. They rated the teams by examining their level of success in accomplishing the project task of delivering cups to the correct tables.

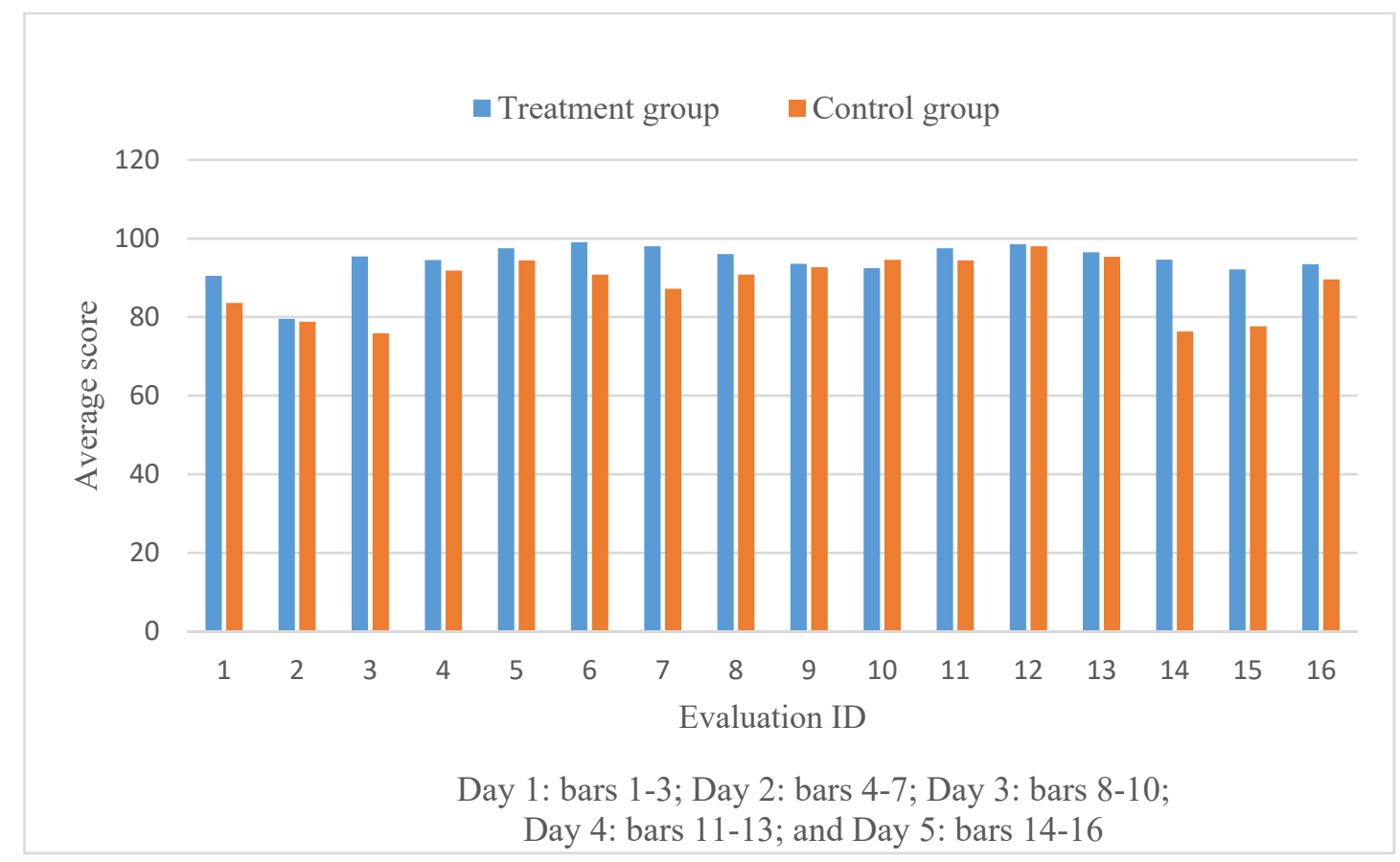

Figure 2: Average evaluation scores of teams in the treatment and control groups.

Most teams in the treatment group built strong and robust structures for their robots. For example, by adding extra material on the opposite end of the claw, one treatment group team created a robot that was deemed "an excellent well balanced robot" (see Figure 3a). Alternatively, one control group team prototyped a robot structure that was "at a risk of toppling" (see Figure 3b). Although this team eventually realized their design flaw and rebuilt their robot, they lost precious time in dismantling and reassembling iteration. In contrast, the teams in the treatment group engaged in frequent iterations early in the design cycle to flexibly consider and assess varied options and minimized loss of valuable time and material resources after committing to physical prototyping. 


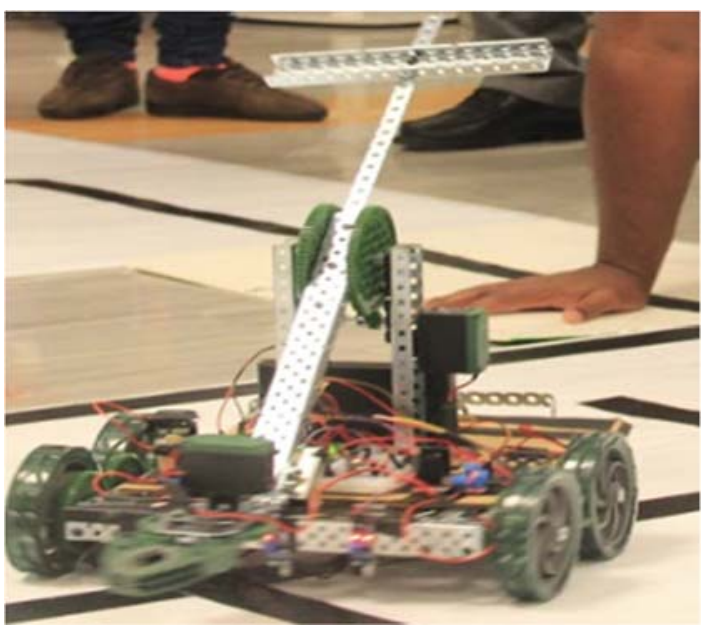

(a)

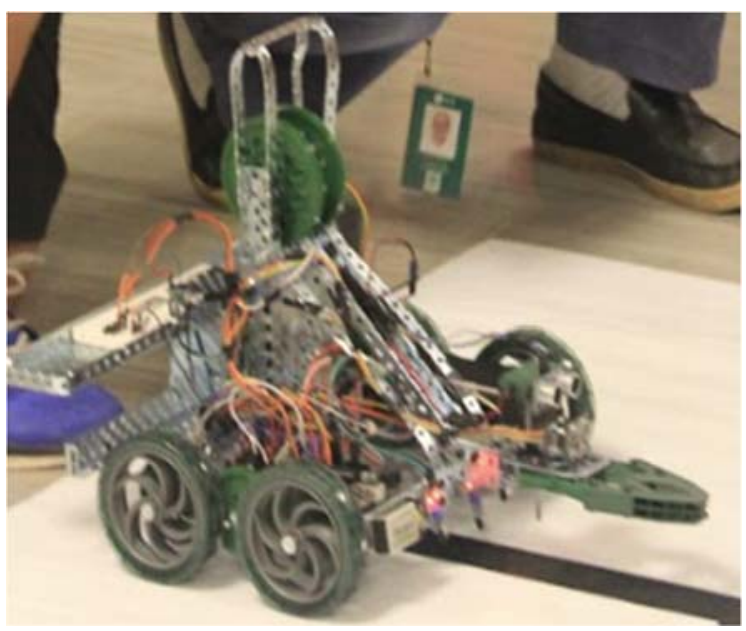

(b)

Figure 3: Comparing robot designs of a team in (a) treatment group and (b) control group.

Most teams in the treatment group were deemed to have designed and implemented better algorithms for their robots. As an example, one treatment group team used a systematic experimentation approach with various sensor combinations to select their sensing strategy and then developed an efficient algorithm that relied on input from five IR sensors. Alternatively, the teams in the control group tried trial-and-error approaches to improve their algorithms without considering the effect of earlier design decisions, e.g., robot structure and drive mechanism, and without examining the effectiveness of various combinations of sensing approaches.

All the aforementioned factors contributed to better overall robot designs and successful performance by the teams in the treatment group. Performing a $t$-test analysis for the average rating of treatment $v s$. the control group for 16 evaluations yields a $t$ value of 2.966 indicating statistically significant differences between the two groups. The corresponding $p$ value for the two tail test is $0.0098(<0.05)$ (Table 2), which allows us to reject the null hypothesis. Finally, Cohen's $d$ value is computed to be 0.986 , indicating a large effect size.

Table 2: Results of $t$ tests of treatment vs. control group scores for 16 assessments.

\begin{tabular}{|c|c|c|c|c|c|c|c|}
\hline $\begin{array}{c}\text { Treatment } \\
\text { group } \\
\text { average }\end{array}$ & $\begin{array}{c}\text { Control } \\
\text { group } \\
\text { average }\end{array}$ & $\begin{array}{c}\text { Treatment } \\
\text { group std. } \\
\text { deviation }\end{array}$ & $\begin{array}{c}\text { Control } \\
\text { group std. } \\
\text { deviation }\end{array}$ & $n$ & $t$ & $p$ & Significance \\
\hline 94.31 & 88.2 & 4.66 & 7.40 & 16 & 2.966 & 0.0098 & Yes \\
\hline
\end{tabular}

\subsection{Illustrative examples of applications of the design canvas model}

In this subsection, we provide two illustrative examples that showcase how the teacher-student teams approached the design projects with the aid of the design canvas model. First we consider a 
team that decided to name their planned robot creation Xpresso. Faced with the newly introduced design canvas approach, the team members began with a literature review to comprehend this technique. After understanding the utility of various elements of the design canvas model, the team devoted time to develop a shared understanding of the project through research, brainstorming, and feedback. For example, they searched for and examined already existing food delivery robots to identify competing products. They studied the pros and cons of these existing robotics devices and considered ways of creating a superior product. They clearly identified the following two primary goals and two secondary goals: (i) the robot must be capable of serving drinks to customers at their tables in dining establishments; (ii) the robot must be capable of retrieving drinks from customers' tables; (iii) the wait time for delivering (and retrieving) drinks must be minimized; and (iv) the product must increase productivity by eliminating errors, e.g., taking drinks to the wrong table. After gathering significant data, the team explored pros and cons of myriad possible solutions with the use of flowcharts and diagrams. Over time, they started to enter responses for nine elements in the design canvas model template (see Table 3) and identified interactions between those elements. They continued to engage in iterative redesign by gathering additional information, analyzing various designs, examining flaws in designs, and exploring ways for improvements. Although the team had established a timeline for their project milestones, because they were new to the design canvas model approach they failed to stick to their timeline. Nonetheless, they were cognizant of when they faced obstacles vs. when they made progress. They actively sought feedback from the facilitators and other teams and considered this to be an essential ingredient of their design approach wherein they flexibly revised their design based on the feedback. They were intentionally observant during all testing and demonstration activities and used such opportunities to conceptualize ways to make their product different from the robots of other teams. As an example, they designed and programmed their robot to collect coffee cups autonomously at the START instead of requiring a manual loading of the cups. This team performed numerous trials, in a systematic manner, to continually evolve their robot before the formal demonstration. Thus, it is evident that this team devoted time and effort up front to understand the problem statement, gather knowledge and information, generate ideas, perform design tradeoffs, and iterate on ideas and design. This team delivered a robot that was successful in delivering cups to correct tables during project demonstration.

Next, we consider a team that decided to name their planned robot creation Serv-e. Table 4 below shows the template for design canvas model completed by this team. They also invested considerable time on literature review, specially to identify the various deficiencies in the currently existing food delivery robots. They considered various algorithms for their robotics system and finally selected one that was deemed through experimentation to be optimally time efficient and that exhibited a high success rate. They conducted experimental trials with great care and used the results to iteratively refine their algorithm. Similar to the Xpresso team, they considered all aspects of the design canvas model and they were quite successful in their project demonstration. 
Table 3: Design canvas model filled by the Xpresso team in the treatment group.

\begin{tabular}{|c|c|c|c|}
\hline \multicolumn{2}{|c|}{$\begin{array}{l}\text { Stakeholders } \\
\text { Drink customers at coffee houses } \\
\text { Management and stakeholders of coffee house } \\
\text { Employees of coffee house } \\
\text { Food and Drug Administration (FDA) } \\
\text { Proprietary coffee order }\end{array}$} & \multirow[t]{2}{*}{$\begin{array}{l}\text { Feature, attributes, and values } \\
\text { claw to pick up and release } \\
\text { drinks } \\
\text { Tray on robot-back to hold more } \\
\text { orders }\end{array}$} & $\begin{array}{l}\text { Design } \\
\text { A robot with claw, } \\
\text { endowed with three } \\
\text { sensors to navigate its } \\
\text { way to customers } \\
\text { A tray in robot-back to } \\
\text { hold more orders }\end{array}$ \\
\hline \multicolumn{2}{|c|}{$\begin{array}{l}\text { Actors } \\
\text { Drink customers at coffee houses } \\
\text { coffee house employees }\end{array}$} & & $\begin{array}{l}\text { Components } \\
\text { Sensors } \\
\text { H-bridge shield } \\
4 \text { motors } \\
\text { Arduino }\end{array}$ \\
\hline $\begin{array}{l}\text { Modes } \\
\text { system may be idle } \\
\text { for long periods } \\
\text { Must have variable } \\
\text { steering choice }\end{array}$ & $\begin{array}{l}\text { Interactions } \\
\text { Employees use an } \\
\text { input system to } \\
\text { communicate tablel } \\
\text { customer }\end{array}$ & $\begin{array}{l}\text { Inputs/outputs } \\
\text { input/order being placed by } \\
\text { employees } \\
\text { input/sensor on robot } \\
\text { output/order being delivered to } \\
\text { customer } \\
\text { output/robot reaching correct } \\
\text { table }\end{array}$ & $\begin{array}{l}\text { Functions } \\
\text { Receive table number as } \\
\text { input from waiter and go } \\
\text { to that table to deliver } \\
\text { coffee }\end{array}$ \\
\hline
\end{tabular}

Table 4: Design canvas model filled by the Serv-e team in the treatment group.

\begin{tabular}{|c|c|c|c|}
\hline $\begin{array}{l}\text { Stakeholders } \\
\text { Restaurants } \\
\text { Hospitals } \\
\text { cafes } \\
\text { Factories }\end{array}$ & & \multirow{2}{*}{$\begin{array}{l}\text { Feature and attributes } \\
\text { Higher productivity } \\
\text { Lower maintenance cost } \\
\text { Less problems } \\
\text { Safer } \\
\text { Precision } \\
\text { Accuracy } \\
\text { Sensitivity } \\
\text { Specificity } \\
\text { No false positive } \\
\text { No false negative } \\
\text { Mechanical advantage } \\
\text { Low \% error } \\
\text { Values } \\
3-4 \text { robots/restaurant }\end{array}$} & $\begin{array}{l}\text { Design } \\
\text { using variables } \\
\cdot \text { odd on left, even on right } \\
\cdot+1 / 2 \text { to find number of } \\
\text { crosses to pass } \\
\text { claw elevation } \\
\text { Payload } \\
\text { Mass } \\
\text { center of mass }\end{array}$ \\
\hline $\begin{array}{l}\text { Actors } \\
\text { Nurses } \\
\text { Baristas } \\
\text { Waiters } \\
\text { Manufacturers } \\
\text { Managers }\end{array}$ & & & $\begin{array}{l}\text { Components } \\
3 \text { motors } \\
3 \text { IR sensors } \\
\text { Claw } \\
\text { chassis }\end{array}$ \\
\hline $\begin{array}{l}\text { Modes } \\
\text { indoor }\end{array}$ & $\begin{array}{l}\text { Interactions } \\
\text { Lift materials } \\
\text { carry food to } \\
\text { customers } \\
\text { serve medication } \\
\text { storing cargo in } \\
\text { warehouse }\end{array}$ & $\begin{array}{l}\text { Inputs/outputs } \\
\text { IR signals }+ \text { black tape } \rightarrow \\
\text { navigation } \\
\text { Remote control } \rightarrow \text { arrive at } \\
\text { location }\end{array}$ & $\begin{array}{l}\text { Functions } \\
\text { Follows line } \\
\text { close/open claw } \\
\text { Turn in correct direction }\end{array}$ \\
\hline
\end{tabular}




\section{Conclusion and Future work}

We acknowledge that the present study has some limitations. The number of teams in the treatment and control groups were not uniform. This resulted from the number of teams being an odd number. Moreover, various teams in each group did not have a uniform number of participants because, contrary of our expectations, schools participating in the workshop did not uniformly have teams composed of two teachers and four students. Finally, we had instructed the members of the treatment groups not to interact with the members of the control group and vice versa. Although we carefully monitored that this kind of interaction did not take place during the workshop hours, it is possible that once the participants left our research site discussion between the members of treatment and control group teams may have taken place. Nonetheless, based on our daily observations, we have no information that such interactions took place.

The results of this paper illustrate that the use of design canvas model allowed teams in the treatment group to be successful in their robotics design project. Since the concept of design canvas was introduced following the introduction of the robotics project challenge, the teams in the treatment group initially took some time to understand how to implement this method. Like the other teams, the treatment group teams were accustomed with classical ways of approaching and addressing design problems, thus they were not comfortable and ready to immediately adopt the new technique. However, as they gradually began to understand the utility and power of this new method, they started to incorporate the design canvas approach in their design solution strategy. Instead of approaching the problem in a linear manner by starting with some solution strategy, the treatment group teams invested time to understand the nuances of the problem. They engaged in significant amount of research and discussions among themselves to comprehend the problem before formally attempting any solutions to the problem. They explored various possible solutions through brainstorming and engaged in out-of-the-box-thinking. After fully understanding the problem and grasping their selected design, they launched the design process while maintaining their flexibility to alter their solution approach as needed. They used descriptive texts, graphics, circuit schematics, numerical quantities, mathematical calculations, algorithmic flowcharts, etc., to analyze their designs. They identified the nine elements of design canvas and the interactions between those elements. They worked on the tradeoffs between the design canvas elements and through numerous iterations improved their designs. They carefully considered feedback from diverse stakeholders and revised their designs based on the same. The participants from the treatment group clearly gained valuable experience in utilizing the design canvas method through their summer workshop experience. In future iterations of workshop, we will consider not only the

treatment and control groups as above but also introduce the design canvas model to the control group in Week 4 of their experience and contrast their designs from Week 3 vs. Week 4. 


\section{Acknowledgments}

This work is supported in part by the National Science Foundation grants ITEST DRL: 1614085, DRK-12 DRL: 1417769, and RET Site EEC: 1542286; and NY Space Grant Consortium grant 76156-10488. The authors thank the high school teachers, their students, and the members of evaluation team for their participation in this study.

\section{References}

[1] F.B.V. Benitti, "Exploring the educational potential of robotics in schools: A systematic review," Computers and Education, vol. 58, no. 3, pp. 978-988, 2012.

[2] M. Riojas, S. Lysecky, and J. Rozenblit, "Educational technologies for precollege engineering education," IEEE Transactions on Learning Technologies, vol. 5, no. 1, pp. 20-37, 2012.

[3] National Research Council, A Framework for K-12 Science Education: Practices, Crosscutting Concepts, and Core Ideas. Washington, DC: National Academies Press, 2012.

[4] NGSS Lead States, Next Generation Science Standards: For States, by States. Washington, DC: National Academies Press, 2013.

[5] Massachusetts Department of Education, Massachusetts Science and Technology/Engineering Curriculum Framework. Malden, MA, 2006.

[6] Museum of Science, "Engineering is Elementary." [Online]. Available: https://www.eie.org/eiecurriculum/engineering-design-process. [Accessed: 04-Mar-2013].

[7] D. Shetty and R.A. Kolk, Mechatronics System Design. Stamford, CT: Cengage Learning, 2010.

[8] T. Byers, T. Seelig, S. Sheppard, and P. Weilerstein, "Entrepreneurship: Its role in engineering education," The Bridge, vol. 43, no. 2, pp. 35-40, 2013.

[9] W.A. Kline et al., "Development of a design canvas with application to first-year and capstone design courses," in Proc. ASEE Annual Conference, 2017. https://peer.asee.org/28159.

[10] N. Reich-Stiebert and F. Eyssel, "Robots in the classroom: What teachers think about teaching and learning with education robots," in Proc. International Conference on Social Robotics, 2016, vol. LNAI 9979, pp. 671680.

[11] E. Afari and M.S. Khine, "Robotics as an educational tool: Impact of Lego Mindstorms," International Journal of Information and Education Technology, vol. 7, no. 6, pp. 437-442, 2017.

[12] M. Petre and B. Price, "Using robotics to motivate 'back door' learning," Education and Information Technologies, vol. 9, no. 2, pp. 147-158, 2004.

[13] T.V. Menzies and J.C. Paradi, "Entrepreneurship education and engineering students: Career path and business performance," International Journal of Entrepreneurship and Innovation, vol. 4, no. 2, pp. 121-132, 2003.

[14] E.L. Wang and J.A. Kleppe, "Teaching invention, innovation, and entrepreneurship in engineering," Journal of Engineering Education, vol. 90, no. 4, pp. 565-570, 2001.

[15] S.P. Nichols and N.E. Armstrong, "Engineering entrepreneurship: Does entrepreneurship have a role in engineering education?," IEEE Antennas and Propagation Magazine, vol. 45, no. 1, pp. 134-138, 2003.

[16] L. Naldi, M. Nordqvist, K. Sjöberg, and J. Wiklund, "Entrepreneurial orientation, risk taking, and performance in family firms," Family Business Review, vol. 20, no. 1, pp. 33-47, 2007.

[17] N. Duval-Couetil, T. Reed-Rhoads, and S. Haghighi, "Engineering students and entrepreneurship education: Involvement, attitudes and outcomes," International Journal of Engineering Education, vol. 28, no. 2, pp. 
425-435, 2012.

[18] B. Carryer, "State of entrepreneurship in robotics," 2012. [Online]. Available: http://newventurist.com/2012/06/state-of-entrepreneurship-in-robotics/. [Accessed: 17-Dec-2018].

[19] V. Souitaris, S. Zerbinati, and A. Al-Laham, "Do entrepreneurship programmes raise entrepreneurial intention of science and engineering students? The effect of learning, inspiration and resources," Journal of Business Venturing, vol. 22, no. 4, pp. 566-591, 2007.

[20] D.P. Crismond and R.S. Adams, "The informed design teaching and learning matrix," Journal of Engineering Education, vol. 101, no. 4, pp. 738-797, 2012.

[21] A. Osterwalder and Y. Pigneur, Business Model Generation: A Handbook for Visionaries, Game Changers, and Challengers. Hoboken, NJ: John Wiley \& Sons, Inc., 2010.

[22] A.W. Ulwick, "What is outcome-driven innovation?," White Paper. Strategyn, 2009.

[23] T. Greenwald, "Business model canvas: A simple tool for designing innovative business models," Forbes, 2012. [Online]. Available: https://www.forbes.com/sites/tedgreenwald/2012/01/31/business-model-canvas-asimple-tool-for-designing-innovative-business-models/\#5e3fb04316a7. [Accessed: 17-Dec-2018].

[24] D.J. Bland, "The business model for robot food," Precoil, 2017. [Online]. Available: https://medium.com/precoil/the-business-model-for-robot-food-136d461fbfb0. [Accessed: 17-Dec-2018].

[25] W.D. Schindel, "What is the smallest model of a system?," in Proc. INCOSE International Symposium, 2011, vol. 21, no. 1, pp. 99-113.

[26] R. Siegwart, I.R. Nourbakhsh, and D. Scaramuzza, Introduction to Autonomous Mobile Robots. Cambridge, MA: MIT Press, 2011.

[27] J.F. Kelly, 3D Modeling and Printing with Tinkercad: Create and Print Your Own 3D Models. Indianapolis, Indiana: Que Publishing, 2014.

[28] J. Whitaker, The Electronics Handbook. Boca Raton, FL: CRC Press, 2005.

[29] M. Margolis, Arduino Cookbook: Recipes to Begin, Expand, and Enhance Your Projects. Sebastopol, CA: O'Reilly Media, Inc., 2011.

[30] "VEX Robotics," VEX Robotics. [Online]. Available: https://www.vexrobotics.com/. [Accessed: 20-Dec2018].

[31] H.I. Ansoff, "Strategies for diversification," Harvard Business Review, vol. 35, no. 5, pp. 113-124, 1957.

[32] M.E. Porter, "How competitive forces shape strategy," Harvard Business Review, vol. 57, no. 2, pp. 137-145, 1979.

[33] M.A. Schilling and M. Esmundo, "Technology S-curves in renewable energy alternatives: Analysis and implications for industry and government," Energy Policy, vol. 37, no. 5, pp. 1767-1781, 2009.

[34] K. Lonsdorf, "Hungry? Call your neighborhood delivery robot," NPR, 2017. [Online]. Available: https://www.npr.org/sections/alltechconsidered/2017/03/23/520848983/hungry-call-your-neighborhooddelivery-robot. [Accessed: 20-Dec-2018].

[35] "Barista: The first robot serving coffee to the tables in the world," The Construct. [Online]. Available: http://www.theconstructsim.com/barista-the-first-robot-serving-coffee-in-the-world/. [Accessed: 20-Dec2018].

[36] I. Igel, R. Poveda, V. Kapila, and M. G. Iskander, "Examining the Efficacy of a LEGO Robotics Training for Volunteer Mentors and K-12 Teachers," in ASEE Annual Conference and Exposition, 2012. https://peer.asee.org/21355. 
Appendix 1: Design canvas model template [9]

\begin{tabular}{|c|c|c|c|}
\hline \multicolumn{2}{|c|}{ Stakeholders } & \multirow[t]{2}{*}{$\begin{array}{l}\text { Feature, attributes, and } \\
\text { values }\end{array}$} & \multirow{2}{*}{$\begin{array}{l}\text { Design } \\
\text { Components }\end{array}$} \\
\hline Actors & & & \\
\hline Modes & Interactions & Inputs/outputs & Functions \\
\hline
\end{tabular}




\section{Appendix 2: Design approach evaluation}

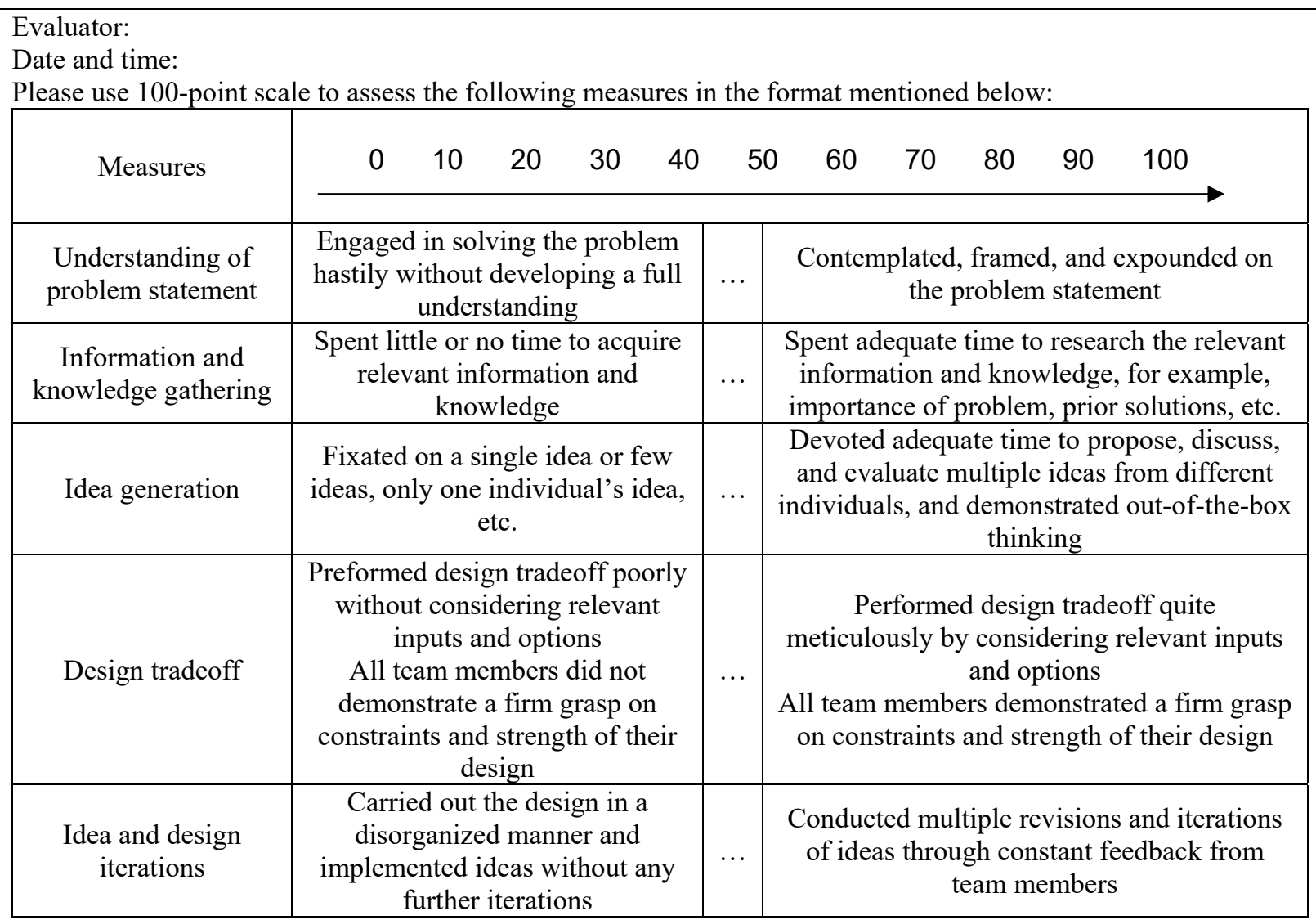

\begin{tabular}{|c|c|c|c|c|c|}
\hline Team & $\begin{array}{c}\text { Understanding of } \\
\text { problem statement }\end{array}$ & $\begin{array}{c}\text { Information and } \\
\text { knowledge gathering }\end{array}$ & $\begin{array}{c}\text { Idea } \\
\text { generation }\end{array}$ & $\begin{array}{c}\text { Design } \\
\text { tradeoff }\end{array}$ & $\begin{array}{c}\text { Idea and design } \\
\text { iterations }\end{array}$ \\
\hline 1 & & & & & \\
\hline 2 & & & & & \\
\hline 3 & & & & & \\
\hline 4 & & & & & \\
\hline 5 & & & & & \\
\hline 6 & & & & & \\
\hline 7 & & & & & \\
\hline 8 & & & & & \\
\hline 9 & & & & & \\
\hline
\end{tabular}


Appendix 3: Grading rubric used to assess the design approach and process

\begin{tabular}{|c|c|c|c|c|c|c|c|c|c|c|c|}
\hline & 0 & 10 & 20 & 30 & 40 & 50 & 60 & 70 & 80 & 90 & 100 \\
\hline Measures & \multicolumn{2}{|c|}{ No effort } & \multicolumn{2}{|c|}{ Poor } & \multicolumn{2}{|c|}{ Insufficient } & \multicolumn{2}{|c|}{ Sufficient } & \multicolumn{2}{|c|}{ Good } & Excellent \\
\hline $\begin{array}{l}\text { Understanding } \\
\text { of problem } \\
\text { statement }\end{array}$ & \multicolumn{2}{|c|}{$\begin{array}{l}\text { No time spent } \\
\text { on discussing } \\
\text { or } \\
\text { understanding } \\
\text { problem, lacks } \\
\text { problem } \\
\text { understanding }\end{array}$} & \multicolumn{2}{|c|}{$\begin{array}{l}\text { Limited time } \\
\text { spent on } \\
\text { discussing } \\
\text { and } \\
\text { understanding } \\
\text { problem, } \\
\text { lacks clear } \\
\text { understanding } \\
\text { of problem }\end{array}$} & \multicolumn{2}{|c|}{$\begin{array}{l}\text { Spent time on } \\
\text { discussing and } \\
\text { understanding } \\
\text { problem but } \\
\text { failed to } \\
\text { convey clear } \\
\text { understanding }\end{array}$} & \multicolumn{2}{|c|}{$\begin{array}{l}\text { Spent } \\
\text { sufficient time } \\
\text { to discuss and } \\
\text { understand } \\
\text { problem and } \\
\text { conveyed } \\
\text { some } \\
\text { understanding } \\
\text { of key } \\
\text { elements }\end{array}$} & $\begin{array}{l}\text { Spent } \\
\text { suffici } \\
\text { to disc } \\
\text { frame, } \\
\text { explain } \\
\text { probles } \\
\text { convey } \\
\text { good } \\
\text { unders } \\
\text { of key } \\
\text { elemen }\end{array}$ & & $\begin{array}{l}\text { Outstanding } \\
\text { understanding } \\
\text { of problem in } \\
\text { all aspects }\end{array}$ \\
\hline $\begin{array}{l}\text { Information and } \\
\text { knowledge } \\
\text { gathering }\end{array}$ & \multicolumn{2}{|c|}{$\begin{array}{l}\text { No time spent } \\
\text { on information } \\
\text { gathering }\end{array}$} & \multicolumn{2}{|c|}{$\begin{array}{l}\text { Limited time } \\
\text { devoted to } \\
\text { gathering } \\
\text { information }\end{array}$} & \multicolumn{2}{|c|}{$\begin{array}{l}\text { Spent time on } \\
\text { gathering } \\
\text { information } \\
\text { but could not } \\
\text { convey its } \\
\text { relevance }\end{array}$} & \multicolumn{2}{|c|}{$\begin{array}{l}\text { Spent } \\
\text { sufficient time } \\
\text { to gather } \\
\text { information } \\
\text { and conveyed } \\
\text { its relevance }\end{array}$} & $\begin{array}{l}\text { Spent } \\
\text { sufficis } \\
\text { to gath } \\
\text { inform } \\
\text { from } \\
\text { approp } \\
\text { resourc } \\
\text { clearly } \\
\text { convey } \\
\text { relevan }\end{array}$ & & $\begin{array}{l}\text { Outstanding } \\
\text { information } \\
\text { gathering in } \\
\text { all aspects }\end{array}$ \\
\hline Idea generation & \multicolumn{2}{|c|}{$\begin{array}{l}\text { Did not } \\
\text { engage in any } \\
\text { idea } \\
\text { generation } \\
\text { exercise }\end{array}$} & $\begin{array}{l}\text { Fixat } \\
\text { single }\end{array}$ & & \multicolumn{2}{|c|}{$\begin{array}{l}\text { Only one } \\
\text { individual } \\
\text { contributed } \\
\text { ideas }\end{array}$} & \multicolumn{2}{|c|}{$\begin{array}{l}\text { Discussed } \\
\text { several ideas } \\
\text { from different } \\
\text { individuals }\end{array}$} & \multicolumn{2}{|c|}{$\begin{array}{l}\text { Discussed and } \\
\text { assessed } \\
\text { multiple ideas } \\
\text { from different } \\
\text { individuals }\end{array}$} & $\begin{array}{l}\text { Outstanding } \\
\text { idea } \\
\text { generation in } \\
\text { all aspects }\end{array}$ \\
\hline Design tradeoff & \multicolumn{2}{|c|}{$\begin{array}{l}\text { Did not } \\
\text { consider } \\
\text { relevant inputs } \\
\text { or options, } \\
\text { team members } \\
\text { did not } \\
\text { demonstrate } \\
\text { understanding } \\
\text { of trade-offs }\end{array}$} & \multicolumn{2}{|c|}{$\begin{array}{l}\text { Considered } \\
\text { limited inputs } \\
\text { and options, } \\
\text { some not } \\
\text { even relevant, } \\
\text { team } \\
\text { members did } \\
\text { not fully } \\
\text { understand } \\
\text { design trade- } \\
\text { offs }\end{array}$} & \multicolumn{2}{|c|}{$\begin{array}{l}\text { Considered } \\
\text { some relevant } \\
\text { inputs and } \\
\text { options, some } \\
\text { team members } \\
\text { demonstrated } \\
\text { understanding } \\
\text { of design } \\
\text { trade-offs }\end{array}$} & \multicolumn{2}{|c|}{$\begin{array}{l}\text { Considered } \\
\text { most relevant } \\
\text { inputs and } \\
\text { options, most } \\
\text { team members } \\
\text { demonstrated } \\
\text { understanding } \\
\text { of design } \\
\text { trade-offs }\end{array}$} & \multicolumn{2}{|c|}{$\begin{array}{l}\text { Considered all } \\
\text { relevant inputs } \\
\text { and options, } \\
\text { all team } \\
\text { members } \\
\text { demonstrated } \\
\text { understanding } \\
\text { of design } \\
\text { trade-offs }\end{array}$} & $\begin{array}{l}\text { Outstanding } \\
\text { design trade- } \\
\text { offs in all } \\
\text { aspects }\end{array}$ \\
\hline $\begin{array}{l}\text { Idea and design } \\
\text { iterations }\end{array}$ & \multicolumn{2}{|c|}{$\begin{array}{l}\text { No systematic } \\
\text { process, } \\
\text { disorganized, } \\
\text { no iterations }\end{array}$} & \multicolumn{2}{|c|}{$\begin{array}{l}\text { Little } \\
\text { application of } \\
\text { systematic, } \\
\text { organized, } \\
\text { iterative } \\
\text { design }\end{array}$} & \multicolumn{2}{|c|}{$\begin{array}{l}\text { Some } \\
\text { reasonable } \\
\text { amount of } \\
\text { systematic, } \\
\text { organized, } \\
\text { iterative } \\
\text { design }\end{array}$} & \multicolumn{2}{|c|}{$\begin{array}{l}\text { Mostly used } \\
\text { systematic, } \\
\text { organized, and } \\
\text { iterative } \\
\text { design }\end{array}$} & \multicolumn{2}{|c|}{$\begin{array}{l}\text { In all aspects } \\
\text { conducted } \\
\text { systematic, } \\
\text { organized, and } \\
\text { iterative } \\
\text { design }\end{array}$} & $\begin{array}{l}\text { Outstanding in } \\
\text { idea and } \\
\text { design } \\
\text { iteration }\end{array}$ \\
\hline
\end{tabular}

